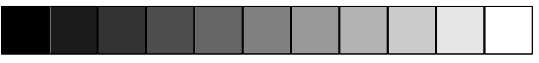

GEOUSP - Espaço e Tempo, São Paulo, No 16, pp. 145 - 152, 2004. 

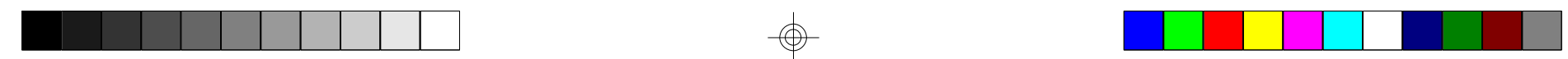

GEOUSP - Espaço e Tempo, São Paulo, No 16, pp. 145 - 152, 2004.

\title{
PRIMEIRAS PROPOSIÇÕES A CERCA DOS FENÔMENOS NATURAIS: A CONSTITUIÇẤO DE UM PENSAMENTO CIENTÍFICO NO SEIO DA ESCOLA DE MILETO.
}

\author{
Ana Cristina Mota Silva *
}

\section{RESUMO:}

Pensar algumas das determinações pré - socráticas a partir da idéia de natureza materialmente constituída e como tal constituição permite uma análise do processo de formação das primeiras investigações científicas.

\section{PALAVRAS-CHAVE:}

Geografia, princípio, cidade, fenômenos naturais, investigação.

\section{ABSTRACT:}

We will think some pré - Socratic determinations from the idea of materially constituted nature and how it permits an analysis of the process of formation of the first scientific investigations.

\section{KEY WORDS:}

Geography, principle, city, investigation and nature phenomena.

O seguinte texto procura analisar algumas das primeiras concepções da constituição de um pensamento científico onde as possíveis determinações da coisa pensada manifestamse inferidas na natureza (physis), postulados que se substanciam na vivência e idéia dos fenômenos naturais. Assim a compreensão da natureza (physis) como uma das primeiras preocupações investigativas do conhecimento e, como através desta noção, portanto, tornase possível o nascimento do processo de investigação dos fenômenos naturais. Isto porque coloca-se para nós um pensamento através do qual as explicações dos elementos da natureza possibilitavam pensar o universo como princípio ${ }^{1}$ de todas as coisas.
A escola de mileto explorava os fenômenos naturais no sentido de constituir um pensamento que se fazia da observação de tais fenômenos. A atualização da coisa pensada dos primeiros princípios - era ao mesmo tempo uma revisão das primeiras representações cartográficas. Desta forma, pensar novas proposições é explorar, sem limite, um pensamento uno com fundamentação matemática, geográfica e astronômica, materializando-se através da realização de cálculos de medição da esfericidade, na elaboração de mapas e posteriormente na efetivação da agrimensura na constituição das cidades. Cf: (KRETSGHMER, 1942, pp. 19 - 20). Estes elementos manuseados correspondiam ao 
mesmo tempo numa atualização do pensamento científico da época, visto que o pensar e a coisa pensada formava uma unidade.

A esta concepção de mundo contrapunhase a existência dos deuses, pois, poder-se-ia dizer que a coexistência de um pensamento racional no interior da Grécia constituía um momento significativo de embate entre as determinações mitológicas e o surgimento da razão (logos).

A noção de princípio propicia uma postura do pensamento em relação às coisas, visto que com esta busca podem-se estabelecer processos lógicos próprios das coisas, mas que em certa medida são independentes delas, pois, passam a ser o elemento determinante de todas as coisas, mesmo aquelas ainda não conhecidas. Embora trate-se de um pensamento substancial, apresenta-se através do mesmo, uma identidade que é a sua: logos.

Mediante esta questão, têm-se claro que o modo como esta noção (physis) aparece no primeiro momento, ou seja, constitui-se como coisa pensada, contrapõe-se à natureza contemporaneamente pensada como natureza dominada, ou melhor, atualizando-a, segunda natureza. Para os gregos a contemplação da natureza - aqui no sentido da observação investigativa - suscitava questões as quais propunham um caminho de se compreender a universalidade ${ }^{2}$ o que certamente, não excluía a compreensão da própria vida, pois, na natureza estabelecia-se um percurso possível de compreensão da unidade anteriormente referida. É então nesse primeiro momento que se pretende localizar analiticamente alguns elementos para discussão.

Os gregos não tiveram uma preocupação com o domínio da natureza. Como ressalta MIRANDA (1996, p.33) A a ciência antiga eminentemente contemplativa, jamais formulou o projeto de uma dominação técnica da natureza nos moldes baconiano-cartesianos. Já VERNANT (1972, p.94) esclarece: A A escola de mileto não viu nascer a razão; ela construiu uma Razão, uma primeira forma de racionalidade. Essa razão grega não é a razão experimental da ciência contemporânea, orientada para a exploração do meio físico e cujos métodos, instrumentos intelectuais e quadros mentais foram elaborados no curso dos últimos séculos, no esforço laboriosamente continuado para conhecer e dominar a natureza. Ainda com base em VERNANT (1972, p.95) afirma que "a filosofia edificou uma matemática sem que procurasse utilizá-la na exploração da natureza."

Nesse sentido, o que se pretende é compreender qual conteúdo é atribuído a esta noção de natureza que postula caminhos para satisfazer as novas necessidades dos gregos ao mesmo tempo em que nega a existência dos deuses e passam os primeiros (filósofos) a identificar a natureza como unidade de todas as coisas.

Inicialmente examinaremos como este debate aparece em Aristófones no diálogo As Nuvens ${ }^{3}$ e em alguns escritos complementares como por exemplo a doxografia dos pré socráticos (essencialmente os escritos de Tales de Mileto e do geógrafo Anaximandro de Mileto, pois o primeiro nos é apontado como o precursor dos filósofos preocupado com as questões relacionadas aos fenômenos naturais e astronômicos. E é também um dos filósofos referenciado no diálogo acima mencionado. Já o segundo além de ter sido seu sucessor discípulo têm uma nova proposição nascida no âmbito da Geografia e a realiza confeccionando mapas, realizando medições através da utilização do gnômon ("antigo instrumento astronômico. Ponteiro de quadrante solar" Cf: (ALMOYNA, s/d, 809), etc.). (Cf: ANAXIMANDRO DE MILETO, 1973, p.19)

Nesse caso mede-se o tempo e as coisas no sentido de constituir historicamente leis para se pensar o universo, para isto o embate de um pensamento investigativo e o mundo profano consolidado torna-se necessário. Os deuses são ao mesmo tempo o mundo grego e a sua negação não se faz de uma forma abrupta já que eles estão disseminados por toda a cidade grega, ou seja, os deuses são pensados quase como realidade absoluta e condição na cidade da vida cotidiana. Como bem lembra COULANGES, (1975, p. 116) A Nunca devemos 
Primeiras proposições a cerca dos fenômenos naturais:

a constituição de um pensamento científico no seio da escola de mileto, pp. 145 - 152

perder de vista que, nos tempos antigos, era o culto que constituía o vínculo unificador de toda e qualquer sociedade. Assim como o altar doméstico mantinha unidos ao seu redor os membros de uma família, (...)"

Isto significa dizer que os fenômenos naturais e a presença divina sintetizam uma unidade terrena. Não se trata de acreditar ou não, ter ou não fé nos deuses gregos. Deve-se compreender que para o homem grego a presença dos deuses efetiva-se tanto quanto as coisas que por eles existiam. Por isso o objeto, ou mesmo a natureza, não se diferenciava do deus que a movia. Pois ela era a própria presença divina transmutada em fenômenos naturais, por exemplo: os ventos, as mudanças das estações, o movimento das águas, o balanço da árvores, etc. Por isso mesmo a religião grega é quase terrena e o Olimpio está logo ali.

Para melhor contextualizar, a discussão a cerca do diálogo As Nuvens de Aristófanes, esta pode efetivar-se em vários momentos: destacase o instante em que Estrepsíades (cidadão comum) procura o pensatório ${ }^{4}$ de Sócrates e quando encontra insiste com o discípulo deste para entrar e, para desperta-Ihe a curiosidade o discípulo de Sócrates inicia explicações sobre as primeiras preocupações dos filósofos para Estrepsíades. Muito embora se insista em dizer que o próprio Sócrates criticava as investigações abstratas sobre os fenômenos naturais e só admitia estudos de geometria e astronomia, o que pode ser visualizado na descrição do pensatório no primeiro instante em que Estrepsíades entra. A Abre-se a porta. Vêem-se os discípulos de Sócrates, em atitudes estranhas, olhando para o chão. No fundo, um leito estreito e uma mesa com mapas, esquadros, réguas, etc...Do outro um cesto dependurado. (ARISTÓFANES, 1980. p.177)

Diante disto, os desdobramentos do pensar filosófico nos é apresentado primeiro quando se busca pensar a superfície da terra a partir de sua representação através de cartas geográficas, por exemplo. Poder-se-ia então identificar este Sócrates primeiro vivendo a seguinte contraposição: deve investigar tanto os fenômenos naturais como também as questões abstratas, sugerem como método investigativo (skepsis) que não se pretende afirmar que os deuses existem teoricamente, mas que se é obrigado a pensar na idéia de deus porque eles têm uma presença generalizada na cidade, mesmo sendo necessário em alguns instantes suspender o juízo para compreender a manifestação dos fenômenos naturais. Vejamos alguns momentos do diálogo As Nuvens criado por Aristófanes:

- Estrepsíades: "Ó Terra, que voz! Como é sagrada, solene e formidável!"

- Sócrates: A Pois de fato só elas [as nuvens] é que são deusas, todo o resto são lorotas!"

- Estrepsíades: "(Assustado) Epa! E Zeus, em nome da Terra! Para vocês o Olímpio não é um deus?"

- Sócrates: AQue Zeus? Não diga tolices! Nem sequer existe um Zeus!"

- Estrepsíades: A Que diz? Mas quem é que chove? Explique-me isto antes de mais nada."

- Sócrates: A Elas, é claro! Mas eu vou demonstrá - lo com sólidas provas. Vejamos. Pois onde, alguma vez, você viu Zeus chover sem Nuvens? $E$, no entanto, ele deveria chover num céu límpido, sem a presença das Nuvens..."

- Estrepsíades: " (Confuso) Mas, diga-me, quem é que troveja, coisa que me faz estremecer?"

- Sócrates: "Elas é que trovejam, quando são roladas...."

- Estrepsíades " (muito espantado): De que jeito, homem de todas as audácias..

- Sócrates: "Quando se enchem de muita água e são obrigadas a mover-se, cheias de chuva, forçosamente, ficam dependuradas para baixo, e, a seguir, pesadas, caem umas sobre as outras, arrebentam e estrondeiam."

- Estrepsíades: (...) A Zeus não existe, e no lugar dele agora reina o Turbilhão! Mas você ainda não me ensinou nada a respeito do estrondo e do trovão..." 
- Sócrates: Então você não me ouviu dizer que as Nuvens, cheias de água, quando caem umas sobre as outras, estrondeiam por causa da densidade?" (ARISTÓFANES, 1980, pp. 184 - 185)

Diante disto, você tem que pensar um deus, ele existe como sociabilidade. Mas, um simples pensar sobre um deus que não existe, ao contrário de se pensar o deus, já elege a razão como momento do pensamento. Aqui pode-se dizer dos fenômenos da natureza como aquilo que identifica a realização desta; nuvens, chuva, etc. sintetizam para Estrepsíades a presença divina e Sócrates ao refutá-los elege como movimento o método investigativo na determinação de tais fenômenos.

Isto se dá também quando Sócrates, na presença de Estrepsíades, passa a buscar explicações físicas para desvendar os mistérios divinos. Vejamos: "Pois nunca teria encontrado, de modo exato, as coisas celestes se não tivesse suspendido a inteligência e não tivesse misturado o pensamento sutil com o ar, o seu semelhante. Se, estando no chão, observasse de baixo o que está em cima, jamais o encontraria. Pois de fato a terra, com violência atrai para si a seiva do pensamento. Padece desse mal até o agrião." (ARISTÓFANES, 1980, p. 179)

Por outro lado, Sócrates primeiro, vive o embate entre o poeta e o filósofo. O poeta Aristófanes descreveu a vida no campo da personagem (Estrepsíades) na sua mais perfeita harmonia: "Eu levava uma vida rústica, agradabilíssima, embolorado, sujo e à vontade, regurgitando de abelhas, de rebanhos e bagaços de azeitona.." (ARISTÓFANES, 1980,p.172). Penso que esta descrição é também uma forma de revelar-se, enquanto poeta e de afirmação do cidadão (esta na figura da personagem de Estrepsíades) em contraposição à forma do filósofo pensar o mundo. A contraposição aqui presente é que o filósofo consegue pensar a universalidade para além dos muros da cidade, evidenciando os seus limites. A noção de princípio busca superar todo imediato através do universal. Ao contrário, a poesia, penso, busca-se colocar no interior da simples unidade da cidade. Se para a primeira os limites tem um sentido de limitação e para tal devem ser superados, para a segunda estes limites tem o sentido de sua identidade. Sócrates primeiro, através do pensar filosófico, coloca em questão a condição do Estrepsíades enquanto cidadão e o fogo no final do diálogo (que põe Estrepsíades no pensatório de Sócrates) simboliza este conflito.

O cidadão é ressaltado no diálogo não através do Sócrates primeiro filósofo, mas através do poeta, ou seja, vive-se a manifestação demorada da presença divina e o ser filósofo. Viver a cidade é também compartilhar deste conflito: por um lado os cidadãos gregos negam o pensamento filosófico para sobreviverem mergulhados na mitologia, pois a tradição asseguraria a harmonia entre os cidadãos e por outro as cidades gregas têm como fundamento a mitologia. Entretanto, esse embate permite perceber a violenta separação vivida no interior do mundo grego revelada no diálogo As Nuvens entre Estrepsíades (cidadão) Aristófanes (poeta) Sócrates (filósofo - fisiólogo) e a família (a qual Estrepsíades defende ao negar Sócrates incendiando o pensatório). A família representa numa aproximação sintética: Estrepsíades, seu filho Fidídipes, sua mulher.

A família constitui aquilo da qual Sócrates primeiro está totalmente distante (Sócrates divide os dias com os discípulos no pensatório investigando sobre o pensamento e os fenômenos da natureza) e concorre como a mais pura forma costumeira de reprodução da vida afundada na mitologia. Como ressalta GOLDSCHMIDT (1984, p. 63) com base em Aristóteles: "sans doute la famille va-t-elle donner naissance au 'village'(...) qui en est une 'colonie'. Mais elle reste cellule originaire de la Cité, et subsiste en tant que partie de celle-ci: On étudiera donc $d$ 'abord 'I'administration d'une maison. Acrescentaria uma outra observação com relação ao significado da família na constituição da sociedade grega ao discutir sobre a cidade e o homem: (...) " ya que la familia es, 'anterior y más necesaria que la ciudad:" LORD (1993, p.140). Penso que aqui além da família o autor também chama atenção para a importância dos costumes na constituição da cidade política. Daí toda a 
Primeiras proposições a cerca dos fenômenos naturais:

a constituição de um pensamento científico no seio da escola de mileto, pp. 145 - 152

discussão entorno da diferença entre physis e o nomos: A distinção implica que a natureza é anterior ao convencional. (STRAUSS, 1993, p.15) Tais observações vem no sentido de melhor esclarecer a relação entre aquilo que era melhor aceito - o poeta - em contraponto com o filósofo. Muito embora a figura socrática representasse a síntese contraditória poeta -filosófo.

Aristófanes, na sua exposição, critica a figura do Sócrates na sua recusa da família, dos deuses, e enfim de uma 'filosofia política' da cidade. Ao mesmo tempo em que o desdobramento desse ser particular socrático manifesta-se como a mais singela universalidade do homem, nas suas inquietações do espírito. As inquietações do espírito referidas aqui dizem respeito ao incessante poder investigativo de Sócrates e pode ser compreendido não somente no diálogo As Nuvens através de Aristófanes, como ainda no diálogo Teeteto de Platão em alguns momentos. Por exemplo, na definição da ciência como opinião verdadeira ou falsa - "Sócrates: 'mas 'voltando ao início da discussão, como é que poderíamos definir a ciência? Não vamos desistir da investigação, presumo eu." E também: "O que temos a fazer é avançar na investigação. Talvez venhamos a esbarrar nalguma coisa que nos revele o que procuramos. Se pararmos por aqui, é que não descobriremos nada..." (PLATÃO, s/d, pp. 156 - 157). Tais inquietações posteriormente revelam uma filosofia fecunda capaz de questionar sobre aquilo que parecia irredutível: a presença divina. A ciência descoberta insurge e possibilita não somente redefinir o lugar do mito, mas se coloca historicamente como caminho de se pensar as fragmentações, contradições presentes: ser poeta e filósofo, etc. O pensar que estava-se constituindo rompe com os limites da cidadania mitológica.

Nesse sentido, a geometria, a astronomia aparecem como pressupostos científicos dos filósofos primeiros e certamente, para o grego, possíveis somente de serem negados na descoberta de seus limites, isto é, na sua transcendência. Isto tornou-se imediatamente possível quando se pensou para além das atribuições das coisas. Por isso, como ponto de partida, buscam-se as determinações dos fenômenos para além da experiência cotidiana. Tales de Mileto pensou o princípio de todas as coisas a partir da água e foi o primeiro passo para a passagem do pensamento mais imediato até o pensamento do pensamento. Isto é, determinado pelas circunstâncias apontou que a filosofia grega permaneceu ainda relacionada à substância. Isto quer dizer, que o princípio identificado por Tales é oriundo da matéria, " $A$ maior parte dos primeiros filósofos considerava como os únicos princípios de todas as coisas os que são da natureza da matéria. Aquilo de que todos os seres são constituídos, e de que primeiro são gerados e em que por fim se dissolvem, enquanto a substância subsiste mudando-se apenas as afecções, tal é, para eles, o elemento (stokheîon), tal é o princípio dos seres;" (ARISTÓTELES, 1973, p.13) a água, e é reconhecido nesse elemento um movimento interno que o expandir-se era expressão da própria alma. Assim, o estudo da geometria, nesse momento, é ao mesmo tempo o estudo também dos fenômenos naturais.

A água nas primeiras determinações do pensamento de Tales de Mileto só existiu como princípio na sua relação com os deuses, ou seja, a água é a própria substância divina, é um ser único. Tales de Mileto é um dos primeiros a enfrentar o pensamento mítico ao mostrar que a vida de todos os seres é determinada pelo elemento água. Isto porque em Tales de Mileto o princípio é a substância material.

Portanto, a explicação está nas coisas. Com Tales de Mileto então, o pensamento busca enfrentar a mitologia a partir do aqui e agora, do imediato. Mas por que discorrer sobre Tales de Mileto? Pensar no geógrafo Anaximandro de Mileto? Se a preocupação nos remete potencialmente ao Sócrates primeiro do Aristófanes? Ou melhor, a natureza pensada nas primeiras determinações dos filósofos fisiólogos no embate com os deuses? Porque o Sócrates primeiro de Aristófanes é um pensador que recebe a influência dos filósofos - geógrafos fisiólogos que pensaram o princípio a partir da physis o que não dispensava uma compreensão do movimento: dos astros, da água, das nuvens, 
do ar, do fogo, etc. A forma de pensar propõe um movimento do pensamento que busca superar o imediato embora a substância imediata continue fundamentando o princípio racional.

COLLINGWOOD, (1950) interpreta o movimento identificado na natureza como manifestação de sua inteligência por si mesma, ou seja, a partir da natureza descobre-se uma razão que é independente de todo princípio mitológico. A procura da universalidade de Tales de Mileto a partir da água e posteriormente do geógrafo Anaximandro denominando-a de infinito (ápeiron), as descobertas de um novo princípio, evidenciam este fato. Como vemos Anaximandro mediante a apresentação de novas descobertas pressupõe o limite da teoria anterior e a investiga sobre a noção de indeterminação. Desde então o novo princípio de todas as coisas passa a ser o infinito (ápeiron). Qual seria o sentido dessas primeiras afirmações?

A introdução do pensamento racional é uma nova maneira de explicação das coisas, poderia-se dizer terrenas. É uma aproximação de expor como o pensamento consegue pensar os fenômenos naturais. É a forma de trazer algo como uma nova determinação, ou melhor, através do processo de reflexão, pretende-se produzir um novo objeto, o ser determinado na sua mais pretensa totalidade que só irá colocarse posteriormente. Tales de Mileto pensou inicialmente a água. Poder-se-ia dizer que Anaximandro pensou o infinito como num grande esforço de superação da matéria em si. Em várias obras se faz referência a Protágoras com relação à afirmação de intitular-se "sofista" e como o primeiro a pensar "o homem como medida de todas as coisas" e "quanto aos deuses, não tinha meios de saber se existiam ou não". (PLATÃO: 1970, p.12).

A busca do princípio nos aponta não só como um começo, mas até onde esse movimento poderá chegar. E a pura atividade, como diria Hegel posteriormente. Muito embora o movimento deste filósofo em específico com relação ao princípio, tenha sido o de apontar o fim dos princípios através do princípio da contradição. Tais pensadores, cada um a sua maneira, estavam na busca de pensar os processos como totalidade, embora esta busca tenha sido a partir de um elemento. Faz parte deste projeto do pensamento grego as atribuições de Platão, por exemplo, no diálogo Teeteto quando se discute sobre as virtudes do verdadeiro filósofo nos ajuda a compreender um dos momentos do pensar do filósofo: "(...) apenas o seu corpo está presente e habita na cidade, enquanto o seu pensamento, desdenhando tudo isto como coisas mesquinhas e sem valor, estende o vôo a todo o universo, como dizia 'Pindaro', 'sondando os abismos da terra e medindo a extensão da sua superfície, perseguindo os astros para lá do céu, perscrutando de todos os modos a natureza e cada ser particular na sua totalidade, sem nunca descer às coisas vizinhas dele." (PLATÃO, s/d, p. 92):

A preocupação do Sócrates primeiro não era investigar a natureza pela natureza, ou seja não recaía somente em identificar os elementos da natureza a partir dos fenômenos naturais como já brevemente foi anunciado acima, mas em descobrir até que ponto essa natureza investigada dos primeiros filósofos dava condições de se pensar ao mesmo tempo a natureza humana. Era esta sim a preocupação socrática e que posteriormente aparecem nos escritos platônicos-aristotélicos. Como bem ressaltam (STRAUSS;CROPSEY, 1993, pp. 1617).: "Al parecer, Sócrates tomó el significado prístimo d 'naturaleza' más en serio que ninguno de sus predecesores: comprendó que la naturaleza és primordialmente 'forma' ó 'idéa'. De ser cierto esto, no se limitó a apartarse del estudio de las cosas naturales, sino que originó una nova clase de estudio de las cosa naturales: una classe de estudio en que, por exemplo, la naturaleza o idea de justicia, o derecho natural, y sin duda la naturaleza del alma humana o del hombre es más importante que, por exemplo, la naturaleza del Sol."

Isto desvanece a intenção de se pensar a natureza como conjunto de coisas. A natureza socrática possibilita o desdobramento da elaboração de conceitos inicialmente sob o método maiêutico (dar à luz com a ajuda da 

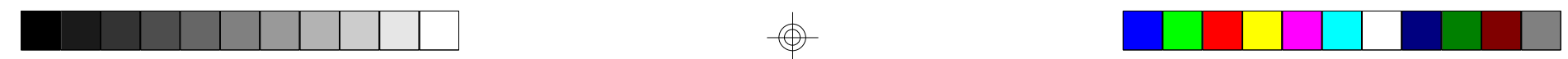

Primeiras proposições a cerca dos fenômenos naturais:

a constituição de um pensamento científico no seio da escola de mileto, pp. 145 - 152

experiência), distancia-se de se pensar a naturalização dos fenômenos, isto é, o fenômeno pelo fenômeno. E mais, investigar que aquilo que se coloca como verdadeiro se desfaz no primado de idéias, e isto permite o nascimento de conceitos e autonomia do pensamento e não dos elementos da natureza com relação aos princípios estabelecidos. Desenvolve-se, nesse momento, uma idéia fecunda de natureza.

\section{Notas}

${ }^{1}$ A idéia de princípio nasce com os primeiros filósofos gregos, têm-se a escola de mileto como referência de constituição deste conceito. A busca de compreender o universo aparece como uma tentativa de constituir os primeiros alicerces deste postulado.

${ }^{2}$ A noção de universalidade aqui não pode ser confundida com universo, mundo. Esta noção refere-se a idéia de síntese hegeliana. Muito embora à busca no interior da escola de mileto por um pensamento nascedouro filosoficamente, não havia aí uma consciência entre pensar o ser e sua manifestação, com seus atributos investigativos, filosóficos, ou seja, uma externalização de sua essência.

${ }^{3}$ É necessário esclarecer que as atribuições referidas ao Sócrates serão na sua maioria feitas ao Sócrates de Aristófanes, o qual o denominei de Sócrates primeiro. Outras identificações estabelecidas sairão das leituras complementares realizadas.

${ }^{4}$ Local na cidade onde Sócrates reunia-se com seus discípulos.

\section{Bibliografia}

ALMOYNA, Julio Martínez. Dicionário de Espanhol - Português. $2^{a}$ edição. Portugal: Editora Porto, s/d. $1506 \mathrm{p}$.

ARISTÓfANES. As Nuvens - In: Sócrates: Os pensadores. 2ed. São Paulo: Ed. Abril Cultural, 1980. pp. 167 - 222.

ANAXIMANDRO DE MILETO (CERCA DE 610 - 547 a C.). In: Os pré - socráticos: Os pensadores.

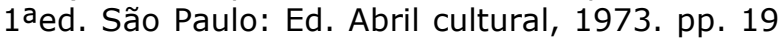
$-53$.

ARISTÓTELES. "Metafísica", I 3. 983 b 6 (DK 11 A 12). In: Tales de Mileto: Os pré - socráticos. Os

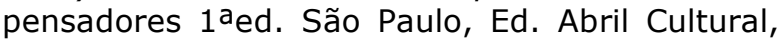
1973. p. 13.

COLLINGWOOD, R. Ideia de la naturaleza. Mexico: Fundo de Cultura Econômica. 1950. 211p

COULANGES, Fustel de. A cidade Antiga. $1^{\text {a ed. }}$ São Paulo, Ed. Hemus, 1975. 310p.
GOLDSCHMIDT, Victor. "A La Theorie Aristotelicienne de L'esclavage et sa methode@". In: Écrits Tome I Études de Philophie Ancienne. $1^{\text {a }}$ edição. Paris: Ed. Librairie Philosophique, 1984.

LORD, Carnes. "Aristóteles[384-322a.c]". In: Historia de la Filosofia Política: STRAUSS, Leo e

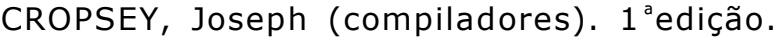
Mexico: Ed. Fundo de Cultura Económica, 1993. 904p.

MIRANDA FILHO, Mário. "Politéia e Virtude: As Origens do Pensamento Republicano Clássico". In: VOUGA, Cláudio e outros (org.), Clássicos do Pensamento Político. $1^{a}$ edição. São Paulo: Ed. Edusp - Fapesp, 1996. pp. 23 - 50.

PLATÃO. Geórgias ou a oratória. $1{ }^{a}$ edição, São Paulo: Difel n. 4,1970. 194p. 


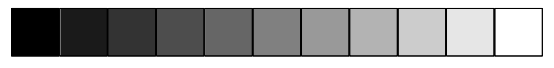

PLATÃO . Teeteto ou da ciência: $1^{\text {a }}$ edição, Lisboa: cadernos culturais. Vol. 113. s/d. 185p.

STRAUSS, Leo e CROPSEY, Joseph (compiladores). "Introducción". In: Historia de la Filosofia Política. 1 1'edição: Mexico: Ed. Fundo de Cultura Económica, 1993. 904p.

TALES DE MILETO (cerca de 625/4-558/6 A.C): In: Os pré - socráticos. Os pensadores. $1^{\mathrm{a} e d .}$ São Paulo: Ed. Abril Cultural, 1973. pp. 11 - 118.
KRETSGHMER, Konrad. Historia De La Geografia.

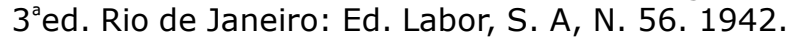
$319 p$.

VERNANT, Jean Pierre. As Origens do Pensamento Grego. $1^{a}$ edição. São Paulo: Ed. Difusão Européia do Livro. 1972.

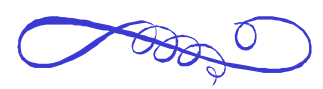

